\title{
The Use of Trans-Esophageal Electrophysiology Study to Identify a High Risk Asymptomatic Wolff Parkinson White Syndrome Patient
}

\author{
Manoj Gupta1,2, Walter Hoyt ${ }^{3}$, Christopher S. Snyder ${ }^{1,2^{*}}$ \\ ${ }^{1}$ Division of Pediatric Cardiology, Department of Pediatrics, Rainbow Babies and Children's Hospital, Cleveland, \\ $\mathrm{OH}, \mathrm{USA}$ \\ ${ }^{2}$ School of Medicine, Case Western Reserve University, Cleveland, OH, USA \\ ${ }^{3}$ Division of Pediatric Cardiology, Department of Pediatrics, School of Medicine, University of Virginia, \\ Charlottesville, VA, USA \\ Email: "Christopher.Snyder@UHhospitals.org
}

Received 26 June 2014; revised 23 July 2014; accepted 19 August 2014

Copyright @ 2014 by authors and Scientific Research Publishing Inc.

This work is licensed under the Creative Commons Attribution International License (CC BY).

http://creativecommons.org/licenses/by/4.0/

(c) $\underset{\mathrm{EY}}{\mathrm{i}}$ Open Access

\begin{abstract}
Patients with a Wolff-Parkinson-White (WPW) pattern on their ECG can experience symptoms such as syncope, palpitations, supraventricular tachycardia, and atrial fibrillation, or they can be asymptomatic (aWPW). All patients with WPW, regardless of the presence or absence of symptoms, are at risk of sudden death. Therefore, it is recommended that younger patients with WPW undergo studies to determine their risk. We report a previously asymptomatic WPW patient identified as high risk for sudden death due to rapid conduction down her accessory pathway during atrial fibrillation induced during a trans-esophageal electrophysiology study.
\end{abstract}

\section{Keywords}

Wolff-Parkinson-White Syndrome, Risk Assessment

\section{Background}

Approximately $0.15 \%$ of the general population is affected with Wolff-Parkinson-White (WPW) syndrome [1]. The presence of symptoms, such as syncope, palpitations, supraventricular tachycardia, atrial fibrillation (A fib)

\footnotetext{
${ }^{*}$ Corresponding author.
}

How to cite this paper: Gupta, M., Hoyt, W. and Snyder, C.S. (2014) The Use of Trans-Esophageal Electrophysiology Study to Identify a High Risk Asymptomatic Wolff Parkinson White Syndrome Patient. Open Journal of Pediatrics, 4, 231-235. 
or sudden death (SCD) in addition to the ECG findings of a short PR interval and the presence of a delta wave meets the criteria initially spelled out by Drs. Wolff, Parkinson and White for the diagnosis of WPW [2]. Many patients with aWPW pattern on their ECG do not manifest symptoms and are subsequently referred to as either asymptomatic ventricular pre-excitation or asymptomatic Wolff-Parkinson-White (aWPW) [3]-[4]. The exact number of patients with aWPW remains unknown, but it is accepted to be approximately $50 \%$ of all WPW patients [3]-[4].

Regardless of symptomatology, all patients with WPW are capable of rapid conduction down their accessory pathway (AP) during atrial fibrillation (A fib) which can lead to ventricular fibrillation and SCD [5]-[7]. Although the overall incidence of SCD in WPW patients is low, estimated at approximately 4.5 per 1000 patient-years, the catastrophic nature of this manifestation suggests an important role for risk stratification and treatment for those who are at risk [8]. A number of methods are currently available to risk assessment of WPW patients, ranging from non-invasive studies such as exercise stress testing (EST) to invasive studies including trans-esophageal or trans-venous electrophysiology studies [9] [10].

We report on a previously asymptomatic WPW patient identified as high risk for SCD due to rapid conduction down her accessory pathway during A fib, shortest pre-excited RR interval of 172 msec, induced during a transesophageal electrophysiology study.

\section{Case Report}

A previously healthy 16-year-old female was referred for evaluation of chest pain. Her history and physical examination were unremarkable, but her ECG revealed WPW (Figure 1). Because she was asymptomatic, the decision was made to risk assessing her proceeding from non-invasive (EST) to invasive (transvenous electrophysiology study) testing.

During her exercise stress test, the accessory pathway persisted to the peak heart rate of $205 \mathrm{bpm}$. Due to the fact that her ECG did not normalize (loss of pre-excitation), her risk could not be determined. She subsequently underwent a minimally invasive transesophageal electrophysiology study (TEEPS).

The TEEPS was performed under general mask anesthesia using a single, 5 French trans-esophageal electrophysiology catheter (TAPCATH $205^{\circledR}$ bipolar pacing and recording catheter). The catheter was passed via the naso-esophageal route and placed in her mid esophagus where atrial tracings were noted. After atrial pacing was confirmed, atrial burst pacing was performed to a cycle length of 200 milliseconds until A fib was induced (Figure 2)

Her shortest preexcited R-R interval during A fib measured 172 msec, placing her at high risk for SCD. Due to this risk, her TEEPS was converted to a transvenous electrophysiology study where her AP was located and successfully ablated (Figure 3).

\section{Discussion}

In symptomatic patients with WPW, current practice dictates that these patients benefit from a transvenous electrophysiology study because the accessory pathway can be both risk-assessed and ablated during the same procedure. Currently, no guidelines exist for the management of aWPW patients.

A previous Italian study [11] which followed 184 asymptomatic children with WPW pattern on their ECG,

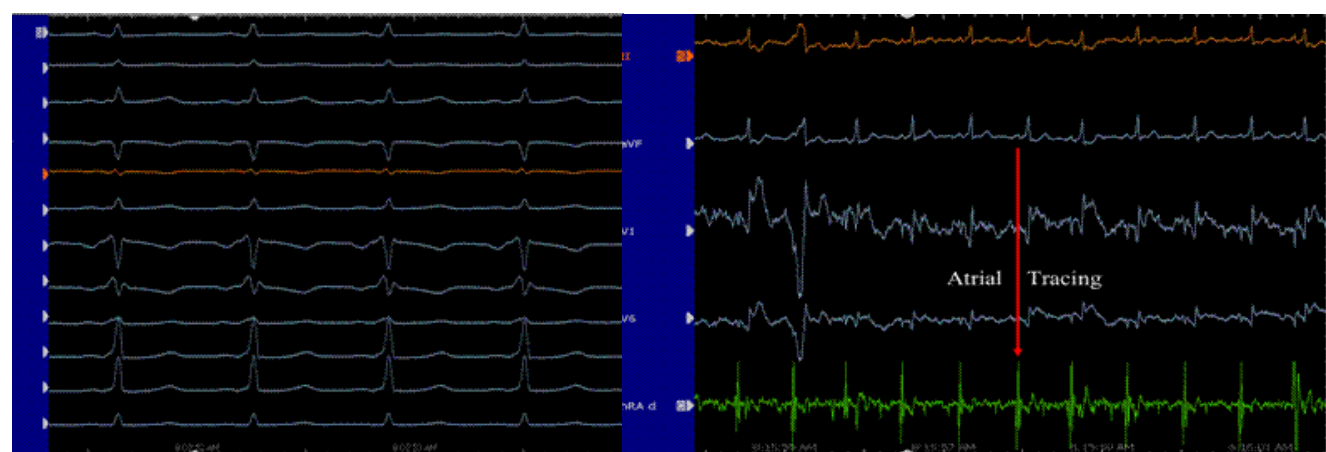

(a)

(b)

Figure 1. (a): WPW pattern. (b): Atrial tracing. 


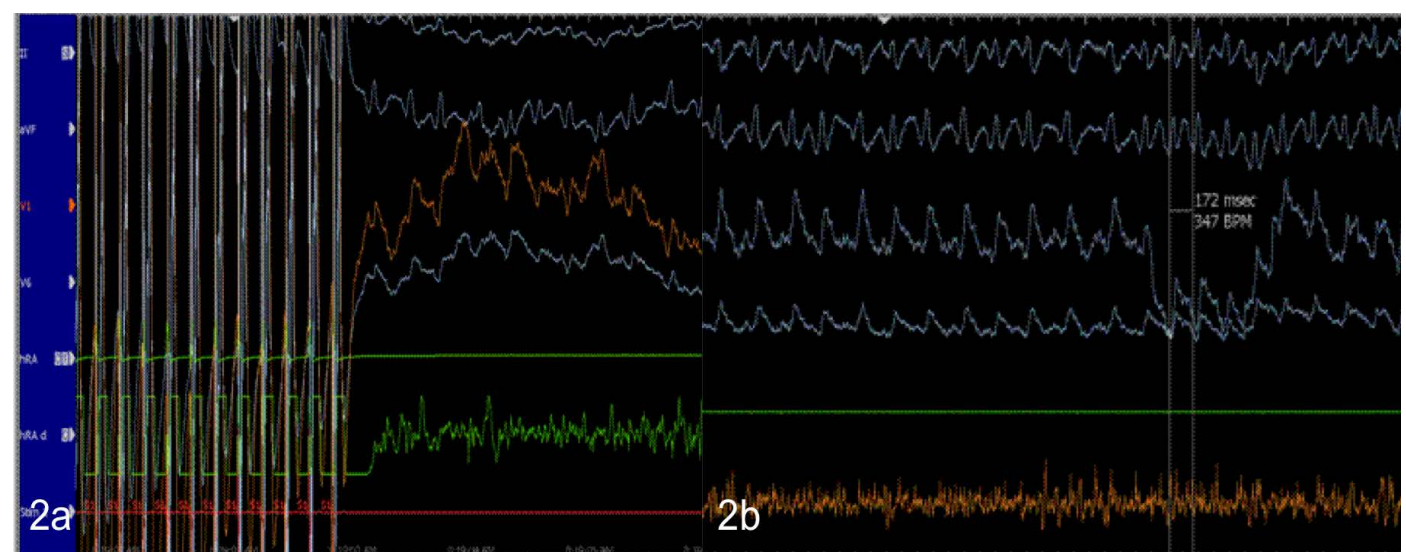

Figure 2. Induction of A fib during atrial burst pacing.

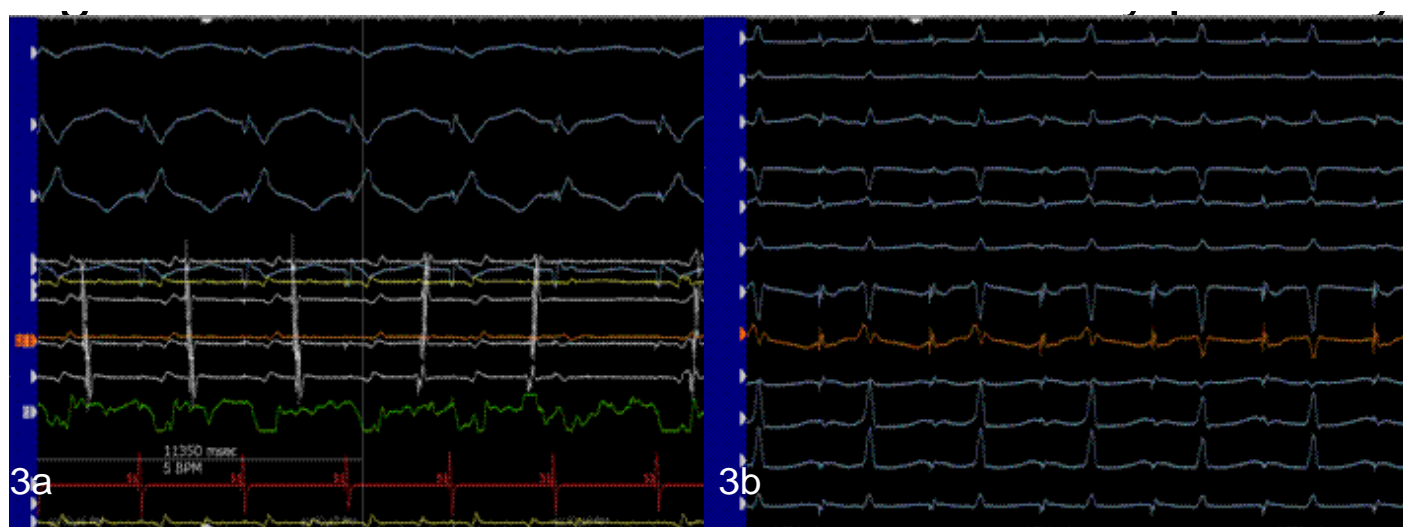

Figure 3. Localization \& ablation of accessory pathway.

found 19 patients during 60 months follow-up who developed potentially life threatening arrhythmias and three of these patients died secondary to these tachyarrhythmias.

In an effort to risk assessing patients with aWPW, our institution developed an algorithm for risk stratification which progresses from least to most invasive testing [12] (Table 1 and Figure 4).

\section{Asymptomatic WPW Algorithm}

This decision tree commences with a non-invasive EST. During this test, the physician monitors the patients ECG for either normalization of the QRS or loss of preexcitation. If the patient does not lose preexcitation during the EST, then their risk cannot be determined. While EST is easily performed in the office on the same day of evaluation, the disadvantage is that the EST provides successful risk assessment in only $8 \%$ of all aWPW patients [13] [14].

If the EST fails to risk assessing a patient, then the next step in our algorithm is to perform a transesophageal electrophysiology study; as this test is minimally invasive, requires no intravenous access, only limited anesthesia, and saving patient from invasive transvenous electrophysiology study. During TEEPS, if A fib is successfully induced and the shortest pre-excited RR interval is equal to or greater than 250 milliseconds then there is no risk of SCD and no further testing is required. If A fib is not inducible or the shortest pre-excited RR interal during A Fib is less than 250 milliseconds, then the next step in the algorithm is to perform a transvenous electrophysiology study [12].

In our patient, we were able to induce A fib with TEEPS where her shortest RR interval was 172 milliseconds, placing her at high risk for sudden cardiac death. Due to her risk, the TEEPS was converted to a transvenous electrophysiology study at which time the accessory pathway was localized and successfully ablated. On her follow up visits, she is asymptomatic from a cardiovascular standpoint with no evidence of preexcitation on her ECG. 
Table 1. Risk factors and grading.

\begin{tabular}{cccc}
\hline Risk factors\Grading & Low risk & Intermediate risk & High risk \\
\hline SPERRI & $>250 \mathrm{~ms}$ & $220-250 \mathrm{~ms}$ & $<220 \mathrm{~ms}$ \\
Intermittent pre-excitation & Yes & - & - \\
Multiple accessory pathway & - & - & Yes \\
Disappearance of AP on EST & Yes & - & - \\
\hline
\end{tabular}

SPERRI: Shortest pre-excited R-R interval; AP: Accessory pathway; EST: Exercise stress test.

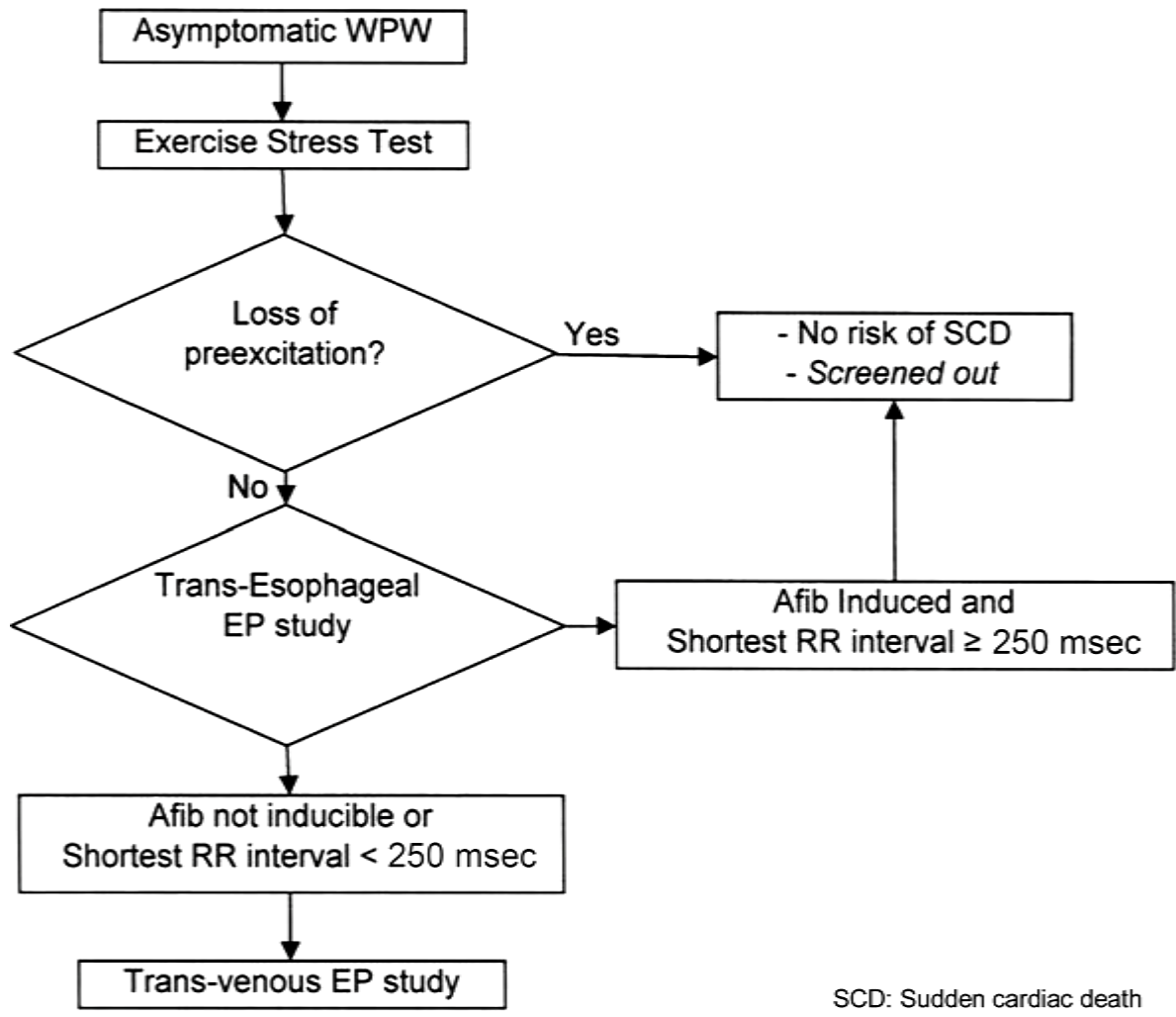

Figure 4. Risk stratification algorithm.

\section{Conclusion}

This report describes the identification of a previously asymptomatic patient with Wolff-Parkinson-White as one who has high risk for sudden cardiac death. This documentation of her risk was performed using the minimally invasive transesophageal procedure. Performance of this procedure on previously asymptomatic patients with Wolff-Parkinson-White syndrome can be very helpful in determining their risk for sudden cardiac death.

\section{References}

[1] Munger, T.M., Packer, D.L., Hammil, S.C., Feldman, B.J., Bailey, K.R., Ballard, D.J., Holmes Jr., D.R. and Gersh, B.J. (1993) A Population Study of the Natural History of Wolff-Parkinson-White Syndrome in Olmsted County, Minnesota, 1953-1989. Circulation, 87, 866-873 http://dx.doi.org/10.1161/01.CIR.87.3.866

[2] Perry, J. (1998) Supraventricular Tachycardia. In: Garson Jr., A., Bricker, J.T., Fisher, D.J. and Neish, S.R., Eds., Science and Practice of Pediatric Cardiology, Williams \& Wilkins, Baltimore, 2059-2101.

[3] Wellens, H.J., Rodriguez, L.M., Timmermans, C. and Smeets, J.L. (1997) The Asymptomatic Patient with Wolff-Parkinson-White Electrocardiogram. PACE, 20, 2082-2086.

http://dx.doi.org/10.1111/j.1540-8159.1997.tb03633.x 
[4] Goudevenos, J.A., Katsouras, C.S., Graekas, G., et al. (2000) Ventricular Preexcitation in the General Population: A Study on the Mode of Presentation and Clinical Course. Heart, 83, 29-34. http://dx.doi.org/10.1136/heart.83.1.29

[5] Pietersen, A.H., Andersen, E.D. and Sandoe, E. (1992) Atrial Fibrillation in the Wolff-Parkinson-White Syndrome. The American Journal of Cardiology, 70, 38A-43A. http://dx.doi.org/10.1016/0002-9149(92)91076-G

[6] Klein, G.J., Bashore, T.M., Sellers, T.D., Pritchett, E.L., Smith, W.M. and Gallagher, J.J. (1979) Ventricular Fibrillation in the Wolff-Parkinson-White Syndrome. The New England Journal of Medicine, 301, 1080-1085. http://dx.doi.org/10.1056/NEJM197911153012003

[7] Bromberg, B.I., Lindsay, B., Cain, M. and Cox, J. (1996) Impact of Clinical History and Electrophysiologic Characterization of Accessory Pathways on Management Strategies to Reduce Sudden Death among Children With Wolff-Parkinson-White Syndrome. Journal of the American College of Cardiology, 27, 690-695. http://dx.doi.org/10.1016/0735-1097(95)00519-6

[8] PACES/HRS(2012) Expert Consensus Statement on the Management of the Asymptomatic Young Patient with a Wolff-Parkinson-White (WPW, Ventricular Preexcitation) Electrocardiographic Pattern. Heart Rhythm, 9, 1006-1024 http://dx.doi.org/10.1016/j.hrthm.2012.03.050

[9] Gaita, F., Giusteto, C., Riccardi, R., Mangiardi, L. and Brusca, A. (1989) Stress and Pharmacologic Tests as Methods to Identify Patients with Wolff-Parkinson-White Syndrome at Risk of Sudden Death. The American Journal of Cardiology, 64, 487-490. http://dx.doi.org/10.1016/0002-9149(89)90426-8

[10] Sharma, A., Yee, R., Guiraudon, G. and Klein, G. (1987) Sensitivity and Specificity of Invasive and Non-invasive Testing for Risk of Sudden Death in Wolff-Parkinson-White Syndrome. Journal of the American College of Cardiology, 10, 373-381 http://dx.doi.org/10.1016/S0735-1097(87)80021-9

[11] Santinelli, V., et al. (2009) The Natural History of Asymptomatic Ventricular Pre-Excitation: A Long-Term Prospective Follow-Up Study of 184 Asymptomatic Children. Journal of the American College of Cardiology, 53, 275-280. http://dx.doi.org/10.1016/j.jacc.2008.09.037

[12] Pappone, C., Santinelli, V., Rosanio, S., Vicedomini, G., Nardi, S., Pappone, A., Tortoriello, V., Manguso, F., Mazzone, P., Gulletta, S., Oreto, G. and Alfieri O. (2003) Usefulness of Invasive Electrophysiologic Testing to Stratify the Risk of Arrhythmic Events in Asymptomatic Patients with Wolff-Parkinson-White Pattern: Results from a Large Prospective Long-Term Follow-Up Study. Journal of the American College of Cardiology, 41, 239-244. http://dx.doi.org/10.1016/S0735-1097(02)02706-7

[13] Bricker, J.T., Co-Burn, J., Garson Jr., A., Gillete, P.C., McVey, P., Malinda, T. and McNamara, D. (1984) Exercise Testing in Children with Wolff-Parkinson-White Syndrome. The American Journal of Cardiology, 55, 1001-1004. http://dx.doi.org/10.1016/0002-9149(85)90734-9

[14] Moltedo, J.M., Iyer, R.V., Forman, H., Fahey, J., Rosenthal, G. and Snyder, C.S. (2006) Is Exercise Stress Testing a Cost-Saving Strategy for Risk Assessment of Pediatric Wolff-Parkinson-White Syndrome Patients? The Ochsner Journal, 6, 64-67. 
Scientific Research Publishing (SCIRP) is one of the largest Open Access journal publishers. It is currently publishing more than 200 open access, online, peer-reviewed journals covering a wide range of academic disciplines. SCIRP serves the worldwide academic communities and contributes to the progress and application of science with its publication.

Other selected journals from SCIRP are listed as below. Submit your manuscript to us via either submit@scirp.org or Online Submission Portal.
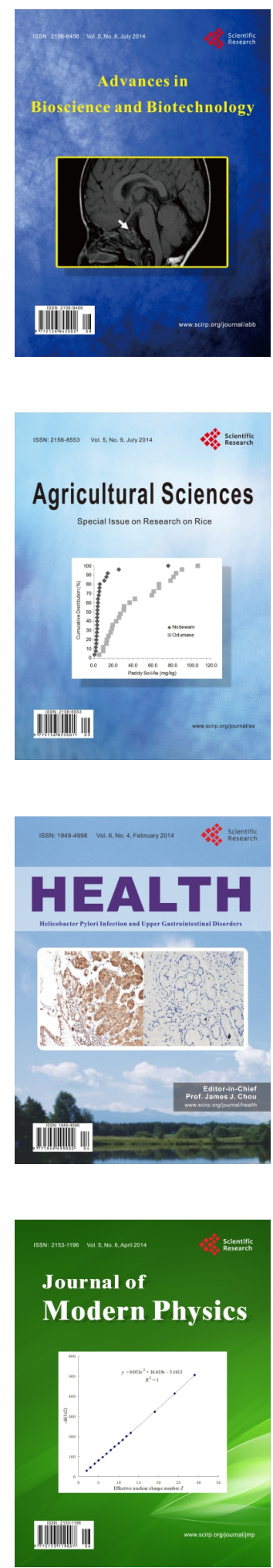
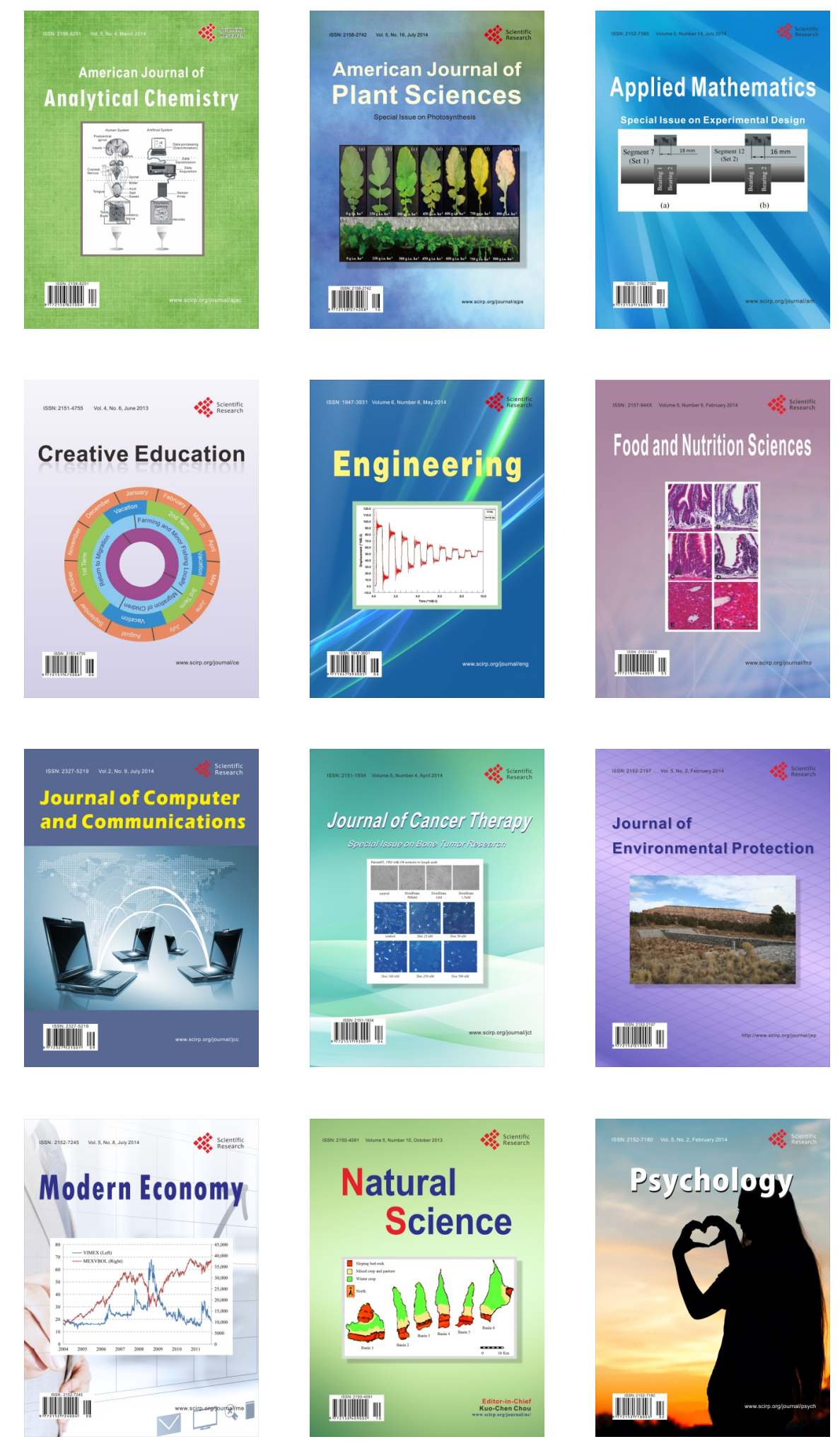